\title{
Teaching Energy Science as Inquiry: Reflections on Professional Development as a Tool to Build Inquiry Teaching Skills for Middle and High School Teachers
}

\author{
Kanesa Duncan Seraphin · Joanna Philippoff • \\ Alex Parisky • Katherine Degnan • Diana Papini Warren
}

Published online: 26 June 2012

(C) The Author(s) 2012. This article is published with open access at Springerlink.com

\begin{abstract}
A hybrid (face-to-face and online) professional development (PD) course focused on energy science for middle and high school teachers $(\mathrm{N}=47)$ was conducted using the teaching science as inquiry (TSI) framework. Data from the PD indicates that online opportunities enhanced participation and that the TSI structure improved teachers' inquiry implementation. Teachers found the TSI modes of inquiry easily accessible and effectively implemented them (modes correspond to the inquiry mechanisms of investigation, such as product evaluation, authoritative, inductive, deductive, and descriptive). On the other hand, the TSI phase structure (i.e. learning cycle) was most helpful for teachers novice to inquiry teaching, suggesting that modification of the PD is needed to promote more in-depth use of the phases in the TSI framework. In terms of content, teacher interest in energy science was high, which resulted in implementation of energy science activities across a range of disciplines. However, teachers' confidence in teaching energy science through inquiry was low compared to similar TSI PD courses on other subjects (mean perceived pedagogical content knowledge $=8.96 \pm 2.07 \mathrm{SD}$ for energy compared to $15.45 \pm 1.83, \quad 16.44 \pm 1.81$ and $15.63 \pm 1.69, \quad$ for
\end{abstract}

K. D. Seraphin $(\bowtie) \cdot J$. Philippoff $\cdot$ K. Degnan Curriculum Research and Development Group (CRDG), University of Hawai'i at Mānoa, 1776 University Ave., Honolulu, HI 96822, USA

e-mail: kanesa@hawaii.edu

K. D. Seraphin · A. Parisky

Sea Grant College Program, University of Hawai ‘i,

2525 Correa Road, Honolulu, HI 96822, USA

D. P. Warren

Women in Technology, Maui Economic Development Board, 1305 North Holopono Street, Suite 1, Kihei, HI 96753, USA elementary astronomy, high school aquatic science, and college aquatic science, respectively). These data support current findings on the complexities of teaching and understanding energy science content and suggest the need for additional teacher PD opportunities in energy science in order to provide opportunities for teachers to increase both their content knowledge and their confidence in teaching energy science.

Keywords Inquiry $\cdot$ Energy $\cdot$ Science $\cdot$ Renewable · Sustainable $\cdot$ Professional development

\section{Introduction}

Global economic and ecological issues have generated increased awareness of depleting energy resources and increased enthusiasm for energy conservation. However, there remains a general lack of understanding with respect to the fundamental concepts of energy science. A survey by the National Environmental Education and Training Foundation (NEETF 2002), for example, found that only $12 \%$ of Americans could pass a basic energy quiz. These results are supported by Manville (2007) and Shelton (2008), who reported that only than $1 / 3$ of Americans are aware that coal combustion is the primary source of electricity in the U.S. This lack of understanding is indicative of an American populace who lacks the background knowledge to understand how energy is converted from one form to another and therefore struggles to compare various sources of usable energy. Indeed, research indicates that our teachers are enthusiastic about energy issues, but that they hold misconceptions about the conceptual meanings of the terms "sustainability" and "renewable sources of energy". As a result there is attention to issues 
such as recycling, but there is relatively little implementation in the classroom of energy science curriculum that deals with energy generation or energy consumption despite teachers' high levels of interest in the subject (see Spiropoulou et al. 2007; Liarakou et al. 2009).

The professional development (PD) intervention described in this paper took place in Hawai ' $i$, where residents embrace a lifestyle that depends on off-island resources, including food, household goods, building supplies and other products. In fact, Hawai'i energy consumption is much more fossil fuel-based than the national averages; $93 \%$ of Hawai 'i's energy consumption relies on petroleum and coal, including $77 \%$ of electricity needs and over $99 \%$ of transportation needs (vs. $55 \%$ for the U.S. as a whole; see State of Hawai 'i 2007). Hawai' i's fuel cost is also the highest in the country (AAA fuel gauge report 2011). However, Hawai' $i$ is also unique in its volcanic composition and geographic position-able to simultaneously take advantage of wind, solar, thermal, and hydroelectric renewable energy resources. In 2008, Hawai' ${ }^{i}$ made a commitment to achieve $70 \%$ clean energy by 2030 (Hawai'i Clean Energy Initiative 2010). Hawai' $i$ residents, therefore, have both a unique opportunity and a unique challenge to manage their islands' resources sustainability.

Teachers in Hawai' $i$ have a corresponding responsibility to educate their students on the mechanics energy resource conversion to usable power sources so that students can effectively make decisions about sustainable and renewable resource issues. Moreover, because teachers are the primary link in preparing our students for energy related jobs (see Chedid 2005), it is vital that teachers have high levels of proficiency and confidence in their ability to teach energy science. Nationally, job growth in the energy sector is projected to increase in tandem with the increase in renewable energy project installations. In the wind energy industry alone, job growth between 2005 and 2009 grew $39 \%$ annually and is projected to continue to grow at a similar rate. Similar job growth projections have been published by the U.S. Department of Labor (2010) for energy engineers in agricultural and solar fields.

Recent research has shown that, in classes where students harbor misconceptions about electrical energy, an inquiry-based approach is more successful than traditional teaching in improving conceptual understanding (see Afra et al. 2009). Our goal, therefore, was to first help teachers improve their understanding of renewable and sustainable energy science and subsequently improve teachers' ability and comfort level with teaching energy science through inquiry in their classrooms. PD activities engaged teachers in learning and teaching about renewable energy technology (e.g. hands-on activities focused on solar and wind) and practicalities associated with renewable energy such as electrical power distribution (e.g. geography and integration with utility energy grids). PD activities also assisted teachers with the alignment of energy science teaching with local and national science education standards (e.g. in scientific inquiry, nature of science, physics, matter and energy conservation, and environmental science, NRC 1996). Because of the documented need to improve teachers' core knowledge of both energy science content and the methodologies used to generate this scientific content knowledge, we incorporated content expert presentations into our PD intervention. These expert presentations were designed to provide teachers with direct access to current information and technology (see recommendations for teacher education on renewable and sustainable energy topics, Spiropoulou et al. 2007; Liarakou et al. 2009).

The pedagogical intent of the PD was for teachers to gain the skills needed to facilitate student learning of energy science through place-based investigations that targeted scientific inquiry skills covered in our teaching science as inquiry (TSI) framework. TSI promotes a model of inquiry teaching through a cycle of five inquiry phases and ten inquiry modes. Our research goal was to investigate the effects of the PD intervention on teachers' use and comfort level with teaching energy science through the process of inquiry. We compared teachers' perceived ability to teach energy concepts through inquiry with other content areas studied in our previous research on TSI PD.

\section{Methods}

\section{Teacher Recruitment}

Teachers were recruited to the PD via flyers sent to all public and private high schools in the counties where the PDs were offered. Emails were also sent to the list-serves for the Hawai'i State Science Teachers Association (HaSTA) and the local chapter of the National Marine Educators Association (OCEANIA) as well as to organizers of other PD courses for dissemination to their teacher contacts. In addition, the TSI Energy PD course was listed on the Hawai'i Department of Education (HIDOE) website of accredited course offerings (formerly PEDRI and currently $\mathrm{PDE}^{3}$ ). Teachers were accepted to the TSI Energy PD course on a first-come basis and there was no prerequisite for taking the course.

\section{PD Intervention}

We combined the Maui Economic Development Board (MEDB) Island Energy Inquiry (IEI) curriculum with the University of Hawai'i-Mānoa (UHM) College of Education's Curriculum Research and Development Group 
(CRDG) TSI framework to produce the TSI Energy PD. The IEI curriculum (www.islandenergyinquiry.org) was developed and piloted in 2009 (Papini Warren et al. 2011). The IEI curriculum includes introductory contextual information about energy science as well as explicit alignment to science standards. Three modules cover the following topics: (1) energy auditing, (2) photovoltaic solar energy, and (3) wind energy. Each module provides background information for the teacher. Kits were also developed to accompany the curriculum and included energy auditing watt meters, photovoltaic panels and multimeters, pinwheel making materials and PVC wind turbine supplies. Participating teachers used the student activities and kits during the PD intervention. Teachers also kept these kits (approximately a $\$ 300$ value per kit) so they could implement the activities with their students.

The TSI pedagogical framework focuses on learning through authentic application of knowledge and skills. We paired TSI with the IEI curriculum to build an overall theme of facilitating authentic inquiry through energy science. The TSI framework is designed to help teachers teach not only basic scientific concepts, but also the process used to gain and refine those concepts over time, thereby enabling students to better apply what they have learned in real-word situations (see Edelson 1998). In TSI teachers are taught to help students evaluate and decide which inquiry tools and techniques to use during their investigations. Teachers are also encouraged to provide students the opportunity for social interaction within the context of science. When teachers effectively teach science through TSI-based inquiry, they guide students' thinking and reasoning through the judicious use of discussion, insight and assistancethereby teaching science as and through inquiry rather than by inquiry (see van Zee et al. 2005).

The general philosophy of the TSI instructional approach involves a multidirectional process integrated with instruction. The TSI model often begins with initiation, when a teacher or student identifies a problem to be solved or asks a question about their surrounding environment. Students engage in the invention of a means to solve their problem or gather information to answer their questions. Investigation is the part of the TSI learning model that involves the actual gathering of new knowledge. Information gathered during the investigation requires interpretation. Interpretation is both a reflective, internal process and an objective, external one. Instruction is integrated into each part of the inquiry sequence. Instruction in the TSI model includes discussion and communication from teacher-to-student as well as student-to-student and student-to-teacher.

Emphasis in TSI is on logical processes rather than rigid, linear procedures or rote scientific steps. For example, investigation can redirect the learning cycle, leading to the initiation of new questions or the invention of new processes or artifacts that can be incorporated into the current investigative framework. Alternatively, investigation may spark an entirely new learning cycle, composed of new questions, new materials, and new investigations. Moreover, instruction can be used to prompt students to think deeper, or explore further, in any of the TSI phases in order to help students reach clear understandings of scientific concepts. This flexibility of the TSI cycle (see Fig. 1) makes it well adapted to the classroom setting (Duncan Seraphin and Baumgartner 2010).

In addition to the phases of inquiry, TSI emphasizes the flexibility of science by encouraging the exploration of a variety of different modes of inquiry. Because science is practiced in many ways, the use of multiple modes of knowledge generation and acquisition is an important aspect of disciplinary inquiry (Windschitl et al. 2007). In addition, investigating the nature of science in its various aspects supports student learning through conceptual change (Tytler 2002).

The TSI modes of inquiry are detailed in Table 1. These modes help to illustrate the variety of ways in which new knowledge can be acquired and employed as well as the ways in which teachers and students (indeed, all people) can legitimately do scientific inquiry. "Product Evaluation", for example, implies a testing of tools and methods, which is a much different form of inquiry than "Authoritative" where a student is learning from a knowledgeable source (i.e. their teacher, a book, a fellow student, etc.). Use of multiple inquiry modes reflects research on the process of knowledge development. Students build knowledge when they construct ideas or arguments using evidence from a variety of sources, and they achieve conceptual change when they re-construct their ideas in light of new knowledge or after taking part in discourse with others (Zembal-Saul et al. 2002).

The TSI Energy PD was accredited by the Hawai'i Department of Education (HIDOE). In total, four courses were taught (one pilot course on Maui Island in 2009 and three courses in 2010 on Oahu, Hawai'i, and Kaua' $i$ Islands). Only teachers from the three 2010 PD interventions were part of the research project described in this paper. The 22-h PD intervention course they participated in was comprised of:

1. Workshop. One 2-day (8-h per day; 16-h total) face-toface workshop, which included:

a. Instruction in TSI pedagogy

b. Energy science content, including presentations by local, island-specific, energy science experts. (The guest presentations delivered during the workshop were recorded and provided online for review and/ or classroom viewing.) 
Fig. 1 TSI phases of inquiry. The five phases of inquiry are arranged in a non-linear format to emphasize flow between phases. Instruction, at the center, is embedded throughout the phases and involves teacherto-student as well as student-tostudent and student-to-teacher instruction

\section{Five Scientific Inquiry Steps (TSI Inquiry Phases)}

\section{Interpretation}

WHAT IF?

Evaluate Results: researchers draw conclusions about the
workability or success of testing

Evaluate Conclusions: community evaluates the conclusions of the research; discussion of alternative explanations and additional info.

\section{Initiation}

WHY?

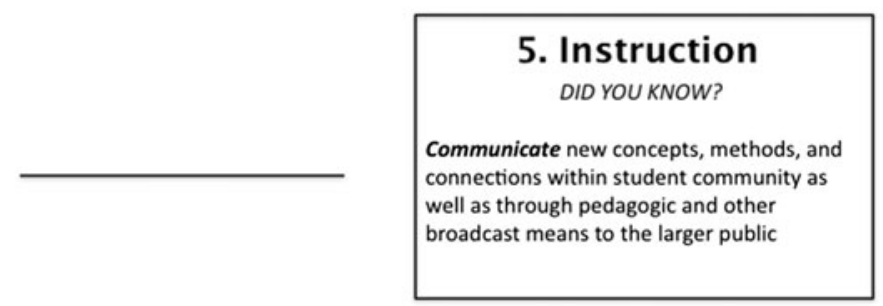

3. Investigation

HOW?

Carry Out a Test (experiment) according to design in the invention phase

Carry Out an Analysis according to the design in the invention phase
2. Invention

WHAT?

Create a Testable Resolution (hypothesis) of the question, problem or need

Create a Test Design (experimental method) or way to determine the workability or the degree of success of the resolution

Table 1 The modes of inquiry addressed in TSI (adapted from Duncan Seraphin and Baumgartner 2010)

\begin{tabular}{|c|c|c|c|}
\hline \multirow{2}{*}{$\begin{array}{l}\text { Inquiry modes } \\
\text { Nouns } \\
\text { (Inquiry learning } \\
\text { through use of ...) }\end{array}$} & \multicolumn{3}{|r|}{ Description } \\
\hline & $\begin{array}{l}\text { Adjectives } \\
\text { (... inquiring) }\end{array}$ & $\begin{array}{l}\text { Verbs } \\
\text { (I am inquiring } \\
\text { by ...) }\end{array}$ & Search for new knowledge... \\
\hline Curiosity & Curious & Being curious & $\begin{array}{l}\text { in external environments through informal or spontaneous } \\
\text { probes into the unknown or predictable }\end{array}$ \\
\hline Description & Descriptive & Describing something & $\begin{array}{l}\text { through creation of accurate and adequate representation of } \\
\text { things or events }\end{array}$ \\
\hline Authoritative knowledge & Authoritative & Learning from others & $\begin{array}{l}\text { through discovery and evaluation of established knowledge via } \\
\text { artifacts or expert testimony }\end{array}$ \\
\hline Experimentation & Experimental & Experimenting & through testing predictions derived from hypotheses \\
\hline Product evaluation & Evaluative & Evaluating products & $\begin{array}{l}\text { about the capacity of products of technology to meet valuing } \\
\text { criteria }\end{array}$ \\
\hline Technology & Technological & Using technology & $\begin{array}{l}\text { in satisfaction of a need through construction, production and } \\
\text { testing of artifacts, systems, and techniques }\end{array}$ \\
\hline Replication & Replicative & Repeating my process & $\begin{array}{l}\text { by validating inquiry through duplication; testing the } \\
\text { repeatability of something seen or described }\end{array}$ \\
\hline Induction & Inductive & Making generalizations & $\begin{array}{l}\text { in data patterns and generalizable relationships in data } \\
\text { association-a hypothesis finding process }\end{array}$ \\
\hline Deduction & Deductive & Drawing conclusions & $\begin{array}{l}\text { in logical synthesis of ideas and evidence-a hypothesis } \\
\text { making process }\end{array}$ \\
\hline Transitive knowledge & Transitive & Applying knowledge & $\begin{array}{l}\text { in one field by applying knowledge from another field in a } \\
\text { novel way }\end{array}$ \\
\hline
\end{tabular}


(1) energy auditing and utility company power distribution specific to the PD location (each island has both its own utility grid and its own unique sources of exploitable energy resources and sustainability challenges),

(2) photovoltaic solar energy, and

(3) wind energy

c. Hands-on, inquiry-based activities in

(1) energy auditing (using watt meters and various appliances),

(2) photovoltaic solar energy (using photovoltaic panels and multimeters),

(3) wind energy (one simple activity using pinwheels and one advanced activity using wind turbine kits containing a motor, multimeter, PVCand balsa wood).

d. Facilitation of energy science integration into classroom instruction, including:

(1) lesson planning,

(2) extensions (e.g. geographic inquiry using maps), and

(3) alignment to standards for grade levels and course needs of individual teachers.

2. Online peer forum. Asynchronous, online delivery of presentations by energy science experts (approximately 1 -h each; 2 -h total). Teachers chose to participate in an online peer forum on two of the four supplemental presentations, which included:

(1) sustainable energy,

(2) solar energy,

(3) policy and climate change, and

(4) ocean thermal energy conversion (OTEC).

3. Implementation. Use of island energy activities and TSI inquiry by teachers with their classes.

4. Elluminate follow-up presentations. Two, 2-h online follow-up meetings via the Elluminate (now renamed Blackboard) virtual classroom software (4-h total). Participants each gave a 10-min powerpoint presentation sharing the results of their curriculum implementation. The follow-up presentations were conducted 2-3 months after the initial 2-day workshop.

Pre-Post Survey Assessment

General data about teacher participants was collected, including participants' grade level(s) and subject(s) taught. Teacher participation was tracked through the PD intervention elements, including the workshop, the online peer forum, classroom implementation, and synchronous Elluminate follow-up meetings. Pre- and post- PD surveys were used to assess participants' pedagogical knowledge and implementation of teaching inquiry-based science. The surveys were based on the work of Scarlett (2008) and included four-point likert scales of teachers' inquiry knowledge and inquiry application (the scale ranged from (1) Strongly Agree to (2) Agree to (3) Disagree to (4) Strongly Disagree, see "Appendix").

Pre-surveys were administered online prior to the PD and Post-surveys were administered online at the conclusion of the Elluminate follow-up portion of the PD. Individual teachers' pre-post responses were compared using a paired $t$ test. In order to gauge teachers' relative comfort level and confidence teaching energy science through inquiry, data from the TSI Energy PDs were compared to teachers who completed TSI PD courses focused on other content areas (elementary level astronomy, high school level aquatic science, and college level aquatic science). Comparisons between groups were made using a General Linear Model (SAS V 9.2) after verifying data sets for internal consistency (Raw Cronbach Coefficient Alpha).

\section{Qualitative Data Analysis of Teacher Responses}

Constant comparative analysis was used as an inductive, data-driven analysis to find recurring patterns. In constant comparative analysis, the researcher takes one piece of data and compares it to all other pieces of data (see Ragin 1987). This method of data analysis was used to construct categories and themes that captured the recurring patterns which emerged from the three sets of data, which were assessed for evidence of energy science knowledge and inquiry implementation. The three sets of data are described below:

HIDOE Credit Portfolios Participants $(\mathrm{N}=12)$ that were seeking HIDOE salary credit for the PD submitted a learning portfolio of their experience. As a part of the portfolio, teachers were required to provide a one-page reflection on the PD course and how it impacted their teaching.

Online Peer Forum Teacher participants used an online discussion board platform to review and discuss videotaped presentations by energy experts and professionals. Each teacher was required to view two presentations and participate in the associated peer-forum.

Elluminate Follow-up Presentations Teachers were taught how to use the Elluminate virtual classroom software prior to their attendance at the virtual follow-ups. (We also hosted an optional, physical node for teachers to gather together and attend the Elluminate follow-ups.) During the online followup, teachers gave presentations about the energy inquiry lessons they implemented in their classrooms. At the end of their 
presentations, teacher presenters interacted with other teacher participants. These online presentations and teacher interactions were recorded and transcribed.

The analysis of the data was cyclical, consisting of initial coding, reflecting, and re-reading, followed by sorting through the codes to discover patterns and themes. In order to reduce bias, multiple investigators were used for verification. Each data set was examined and re-examined by at least two team members so that data analysis consisted of both reflection and communication in the identification of patterns and themes. These methods were used to triangulate the evidence of the data (see Lincoln and Guba 1985).

\section{Results and Conclusions}

\section{Teacher Recruitment}

Forty-seven teachers participated in the TSI Energy PD intervention (Oahu $N=16$, Hawai' $i \quad N=18$, Kaua $i$ $\mathrm{N}=13$ ). Thirty-three of these teachers were female and fourteen were male. Teachers were split between middle $(\mathrm{N}=20)$ and high school $(\mathrm{N}=27$, but see Table 2 for breakdown by grade level). Most teachers were from public schools $(\mathrm{N}=41)$ rather than private schools $(\mathrm{N}=6)$.

\section{Teachers' Implemented Energy Science Across}

\section{a Range of Courses}

The broad range of teachers that participated in this PD course allowed us to connect energy science with teachers of multiple disciplines. Many teachers reported teaching more than one subject, with the majority teaching either or both science and mathematics disciplines $(\mathrm{N}=31$ and $\mathrm{N}=17$ teaching science or math, respectively). Of those teaching science, subjects ranged from biology to physical and earth science. Of those teaching math, subjects ranged from trigonometry and algebra to math workshop (a math tutoring class). Some of the science and math teachers also reported teaching other subjects closely related to energy science, such as engineering, as well as subjects more distantly related, such as drama. Four teachers reported teaching neither science nor math; these teachers taught subjects such as careers in digital media, social studies and culinary arts (see Table 2 for a breakdown by subject).

As a result of this PD, energy inquiry activities were successfully implemented across a wide range of subjects inside as well as outside traditional scientific disciplines. As one teacher wrote, "This experience has helped me to grow as an educator on so many different levels, but a major one was that it got me to use inquiry as a means to try to integrate energy science and other disciplines." For
Table 2 TSI energy teacher participant demographics

\begin{tabular}{|c|c|}
\hline Demographic & Number \\
\hline Male & 14 \\
\hline Female & 33 \\
\hline Public school & 41 \\
\hline Private school & 6 \\
\hline Middle school & 20 \\
\hline 5 th grade & 3 \\
\hline 6th grade & 14 \\
\hline 7 th grade & 17 \\
\hline 8 th grade & 15 \\
\hline High school & 27 \\
\hline 9th grade & 20 \\
\hline 10th grade & 22 \\
\hline 11 th grade & 22 \\
\hline 12th grade & 22 \\
\hline Science & 31 \\
\hline Biology & 8 \\
\hline Physical & 6 \\
\hline Life & 5 \\
\hline Chemistry & 4 \\
\hline Physics & 3 \\
\hline Marine biology & 3 \\
\hline Engineering & 3 \\
\hline Earth science & 1 \\
\hline Math & 17 \\
\hline Unspecified math course & 11 \\
\hline Trigonometry and algebra & 3 \\
\hline Pre-algebra & 2 \\
\hline Math workshop & 2 \\
\hline Geometry & 1 \\
\hline Financial literacy & 1 \\
\hline Other & 18 \\
\hline Social studies & 5 \\
\hline Career courses & 4 \\
\hline Special education & 4 \\
\hline English & 2 \\
\hline Drama & 1 \\
\hline Hawaiian & 1 \\
\hline Geography & 1 \\
\hline Digital media & 1 \\
\hline Auto mechanics and electric cars & 1 \\
\hline Culinary arts & 1 \\
\hline
\end{tabular}

Category numbers (e.g. Middle school) indicate the total numbers of teachers foreach category, followed by a breakdown by grade level or subject area. Note that the number of teachers for middle $(\mathrm{N}=20)$ and high school $(\mathrm{N}=27)$ add to the total number of participants $(\mathrm{N}=47)$, but that many participants reported teaching in multiple categories at multiple grade levels with multiple subjects (thus the number of teachers in each category, at each grade level, or in each subject area is greater than the total number of teachers) 


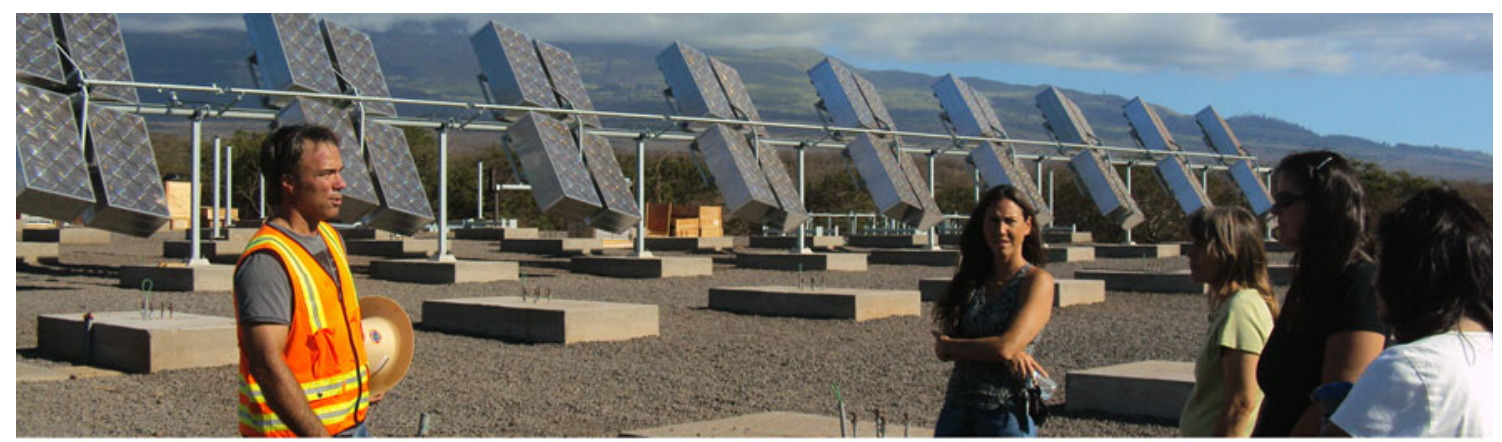

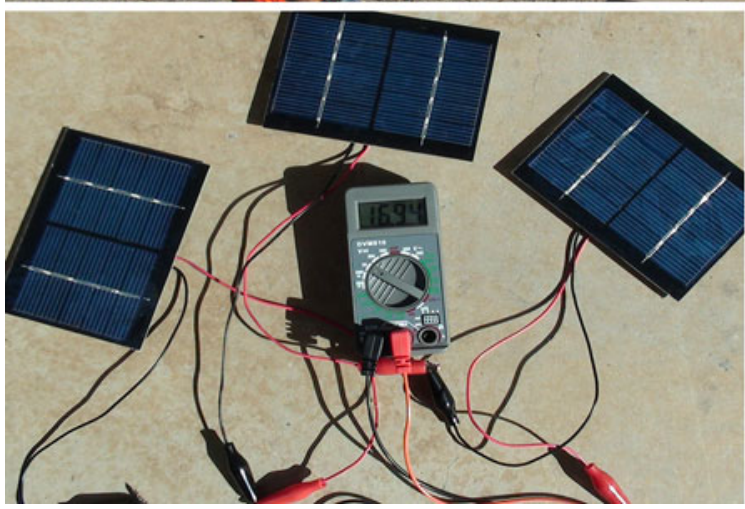

Fig. 2 (Top) Solar energy expert provides information about photovoltaic solar panels to TSI Energy teacher participants. (Bottom left) Solar panels and voltmeter from teacher supply kits in use during the

example, the social studies teacher implemented a unit on wind farm businesses in Hawai ' $i$, the digital media teacher had students investigate various types of renewable energy and present prototypes to the class, the culinary arts teacher designed a project for her students on the use of solar panels to power the irrigation of the school garden, and the two math workshop teachers teamed up as a result of this PD to guide their students through a unit on designing and building solar powered vehicles (see Fig. 2). In their presentation, the math workshop teachers talked about relating science to the real world through inquiry. The teachers focused on the TSI invention phase, on having their students create a testable "resolution of the questions, problem, or need". The two teachers reported that they,

"worked together as a result of the PD ... after our inquiry PD session, (we) added in the investigation portion (of the lesson) and I think that really made the lesson more complete... the inquiry session in the PD helped to tie in science and math... even the ones (students) that are usually disengaged, learned to use new tools, learned to look at materials in new ways... and were pretty hands-on."

We also had four special education (SPED) teachers (two science and two social studies teachers) in our PD that reported being able to successfully teach their students about energy science because of the inquiry approach. The

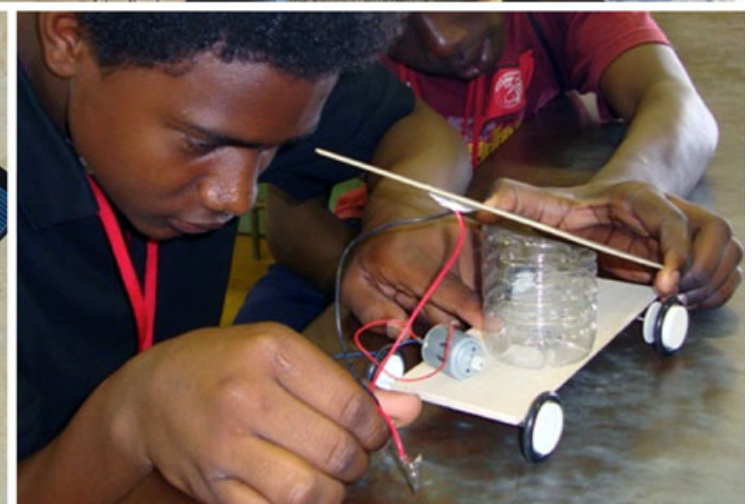

TSI Energy workshop component of the PD. (Bottom right) Students build their self-designed solar powered vehicle as part of their teacher's PD implementation in their 8th grade math workshop class

middle school SPED social studies teacher (who also teaches math) said that it is,

"Hard to do fine motor skills for SPED students-the wind turbine really motivated my students (I used larger numbers (miliamps) because larger numbers got them excited) - they gave up recess and lunch to come work on blade design.... Their complex thinking came out. I am really amazed and impressed."

The high school SPED social studies teacher (who implemented the energy auditing, the solar energy inquiry, and both wind energy inquiry lessons) said,

"If you want to see multiple intelligences at its best come to my SPED classroom... To step out of my comfort zone (to teach through inquiry), that was a big deal. The new teaching perspective (inquiry) was very interesting... The kids were totally engaged, like we can do this, we can do that... they totally ran with it. They really, really enjoyed it."

Teachers were Interested in Energy Science

Teachers' personal interest in energy science was one of the immediately noticeable elements of the PD. Teachers talked about the connection between energy and their own lives. Many discussed the conversion of their homes to low 
efficiency appliances and solar power, for example a high school industrial technology teacher wrote "This (PD) is just what I need... it dovetails into what I am doing... it's fun having this workshop as a beta test." The teachers showed photographic examples of their own energy conservation efforts, and they brought their electric bills to the PD for sharing and analysis. One of the teachers even showed pictures of his home energy conservation efforts with a title that said, "I'm doing my part, are you?". The teachers' interest and excitement was contagious; a modern history teacher remarked "She (a 6th grade science teacher also in the PD) was so psyched, she helped me with my intro to sustainability and measurement of energy in my class."

In the Elluminate follow-up presentations, teachers each gave a 10-min powerpoint presentation of inquiry implementation resulting from their participation in the TSI Energy PD. In their presentations, $89 \%$ of teachers presented on lessons we considered related to core energy topics (i.e., energy research, energy conservation, wind energy conversion and turbines, wind farm business, solar energy, solar cookers, photovoltaic energy conversion, etc.). Of these energy lessons, $50 \%$ were lessons implemented directly from the IEI curriculum (many of these teachers implemented multiple IEI lessons), and $50 \%$ were lessons of the teachers' own creation. Of the direct implementation, $12 \%(\mathrm{~N}=3)$ implemented the energy auditing activity, $36 \%(\mathrm{~N}=9)$ implemented the photovoltaic solar energy activity, and $52 \%(\mathrm{~N}=13)$ implemented at least one of the two wind energy activities. Teacher-created lessons tended to be modifications of IEI curriculum activities and ideas, often using teacher kit supplies-a solar car project, a angular velocity and mathematical connections to wind turbine speed project, and a indigenous wind turbine creation project.

Teachers were interested in learning about a variety of energy science topics, and they appreciated the ability to view (and show their students) the recorded presentations. One teacher, for example, commented, "I showed them (my students) the videos you had online. It really opened their eyes." Of the four expert presentations provided in the online peer forum (where teachers had to view and respond to two out of the four available videos), teachers views and comments were fairly evenly split by topic, with $28 \%(\mathrm{~N}=20)$, $27 \%(\mathrm{~N}=19), 23 \%(\mathrm{~N}=16)$, and $20 \%(\mathrm{~N}=14)$ of the views and comments related to sustainable energy, solar energy, policy and climate change, and OTEC, respectively.

Teachers' use patterns of the recorded expert presentations from their own PD workshops also showed a relatively even distribution, with slightly higher levels of use of wind energy resources, (this may be due to the fact that the wind energy PD component had two lessons (pinwheels and wind turbines) and that the wind turbines were the

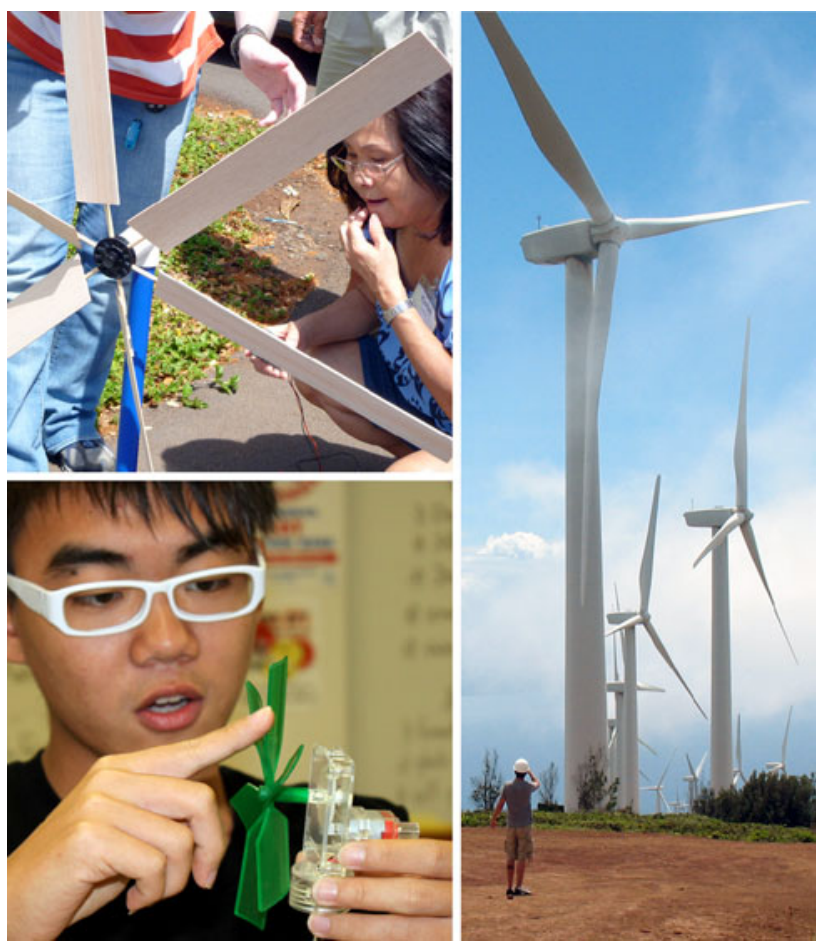

Fig. 3 (Right) Teachers learn about wind turbines from a local wind energy expert. (Top Left) Teachers construct a wind turbine using their teacher supply kits in the TSI Energy workshop component of the PD. (Bottom Left) A student assembles a wind turbine prototype as part of his teacher's PD implementation in high school (9-12th grade) digital media class

most expensive item teachers received in their kits, see Fig. 3). Our online data counter showed that teachers viewed (or showed to their classes) the recorded workshop presentations a total of 199 times. Of these, $31 \%(\mathrm{~N}=63)$ corresponded to energy auditing, $29 \%(\mathrm{~N}=59)$ corresponded to solar energy presentations, and $38 \%(\mathrm{~N}=77)$ corresponded to wind energy presentations.

\section{Teachers' Confidence in Teaching Energy Concepts Through Inquiry Remains Low}

Despite teacher's high interest across energy science topics and their ability to implement large-scale energy projects with their students, teachers in our PD had low confidence in teaching energy science through inquiry, both before and after the PD. Paired t-tests of TSI Energy teachers' inquiry application and inquiry knowledge pre- and post-PD showed negligible changes in teachers' confidence in teaching energy science through the process of inquiry (see Table 3).

It is possible that the lack of gain in inquiry knowledge and application may be due to (1) the short duration of the PD intervention or (2) an artifact of the pre- post-PD survey format, where teachers may have scored themselves 
Table 3 Pre- and post-survey mean \pm standard deviation (SD) for perceived inquiry application and inquiry knowledge of teacher participants in TSI PD courses

\begin{tabular}{|c|c|c|c|c|c|c|}
\hline TSI subject & Grade level & $\mathrm{N}$ & Pre inquiry app. & Post inquiry app. & Difference & $P$ value \\
\hline Astronomy & Elementary & 10 & $15.45 \pm 1.83$ & $18.40 \pm 1.5$ & 2.95 & 0.0468 \\
\hline Aquatic science & High school & 36 & $16.44 \pm 1.81$ & $17.39 \pm 2.07$ & 0.95 & $<0.0001$ \\
\hline Aquatic science & College & 11 & $15.63 \pm 1.69$ & $17.09 \pm 1.76$ & 1.46 & 0.0453 \\
\hline Energy & Middle and high & 26 & $8.96 \pm 2.07$ & $7.88 \pm 1.72$ & -1.08 & 0.1583 \\
\hline TSI subject & Grade level & $\mathrm{N}$ & Pre inquiry know. & Post inquiry know. & Difference & $P$ value \\
\hline Astronomy & Elementary & 10 & $15.75 \pm 1.47$ & $17.10 \pm 1.66$ & 1.35 & 0.6404 \\
\hline Aquatic science & High school & 36 & $15.53 \pm 1.96$ & $16.22 \pm 1.73$ & 0.69 & $<0.0001$ \\
\hline Aquatic science & College & 11 & $15.18 \pm 1.78$ & $16.36 \pm 2.06$ & 1.18 & 0.0064 \\
\hline Energy & Middle and high & 26 & $9.54 \pm 1.48$ & $9.08 \pm 1.85$ & -0.46 & $<0.0001$ \\
\hline
\end{tabular}

$P$ values reflect GLM analysis. Each of these courses covered the same TSI pedagogical framework and consisted of a similar PD format. Note that pre-post values are reported only for teachers who completed both pre- and post-surveys (in the case of the TSI energy, $\mathrm{N}=26$ compared to $\mathrm{N}=47$ who attended the initial PD component and $\mathrm{N}=32$ who completed the online post surveys as six teachers' post surveys were not identifiable)

higher than warranted in the initial pre-survey. However, we used the same survey instrument and methods with teachers from similar locations and backgrounds (i.e. Hawai' $i$ teachers across a range of subjects) in TSI PD on other topics and had significant increases in teachers' perceived inquiry knowledge and application (see Table 3). In fact, even pre-surveys of TSI Energy teachers' perception of their inquiry knowledge (mean $=9.54 \pm 1.48 \mathrm{SD}$ ) and inquiry application (mean $=8.96 \pm 2.07 \mathrm{SD}$ ) were significantly lower (GLM, $P<0.0001$ ) than teachers who participated in TSI on other topics (e.g. elementary-level astronomy, high-school level marine science, and college level marine science; see Table 3).

Comparison of TSI Energy with these other TSI PD groups suggests that the low confidence scores in inquiry for the TSI Energy teachers are due to the energy content. In other words, the energy science content appears to have influenced the teachers' perceptions of their inquiry knowledge and ability. It is also likely that the teachers' lack of confidence in teaching energy science may have been exacerbated by the engagement of the science experts. Although the science experts' presentations were designed to help improve teachers' content knowledge, the presentations also served to remind teachers of the complexities of energy science and the gaps or misconceptions in the teachers' knowledge of energy science. Indeed, teachers asked many basic energy questions of the energy science experts, which indicated the teachers' basic energy content knowledge was low. Teachers also repeatedly said they needed more content knowledge to engage their students effectively in inquiry on the topic of energy.
Gains in Inquiry Pedagogy Despite Low Confidence Levels

Although the teachers' did not rate themselves high in inquiry knowledge or application, the teachers' Elluminate follow-up presentations, online peer forum responses, and HIDOE portfolio reflections revealed, in many cases, rich patterns of inquiry implementation. Coding of teacher participation showed that the most often mentioned results of the TSI Energy PD were related to classroom implementation -- skills, ideas and lessons that teachers learned in the PD and used with students (average of 1.33, 0.91, and 0.51 responses per teacher in portfolios, forum, and Elluminate presentations, respectively; see Table 4). These references were followed in frequency by student interest, TSI pedagogical structure, hands-on application, real world application, and teachers own content knowledge (see Table 4).

Teachers talked about the lessons that they liked, ideas they had learned, materials they had used, and how they had implemented the lessons to improve students' knowledge skills. The teachers said that the "students' questions showed interest" and that students were "highly motivated", "had fun learning", were "were very proud (of their ability)." Many responses about student interest dealt with the amount of time students were willing to commit to their energy project. Teachers commented that,

"My students were real busy in class. I have kids that never participate in class and they were back at lunchtime and after school. I was kind of blown away at how they got into it." 
Table 4 The average reference frequency per teacher related to various content and skills categories

HIDOE Portfolio responses correspond to optional PD portfolios completed by teachers $(\mathrm{N}=12$ total; $\mathrm{N}=4$, 5 , and 3 for Oahu, Hawai ' $i$, and Kaua'i Islands, respectively). Online peer forum responses correspond to teachers' comments in the online forum portion of the $\mathrm{PD}$, and Elluminate follow-up presentation responses correspond to teachers' verbal or written comments during their powerpoint presentations of classroom implementation

\begin{tabular}{llll}
\hline Description of reference & $\begin{array}{l}\text { HIDOE } \\
\text { portfolios } \\
(\mathrm{N}=12)\end{array}$ & $\begin{array}{l}\text { Online peer } \\
\text { forum } \\
(\mathrm{N}=35)\end{array}$ & $\begin{array}{l}\text { Elluminate } \\
\text { follow-up } \\
\text { presentation } \\
(\mathrm{N}=35)\end{array}$ \\
\hline
\end{tabular}

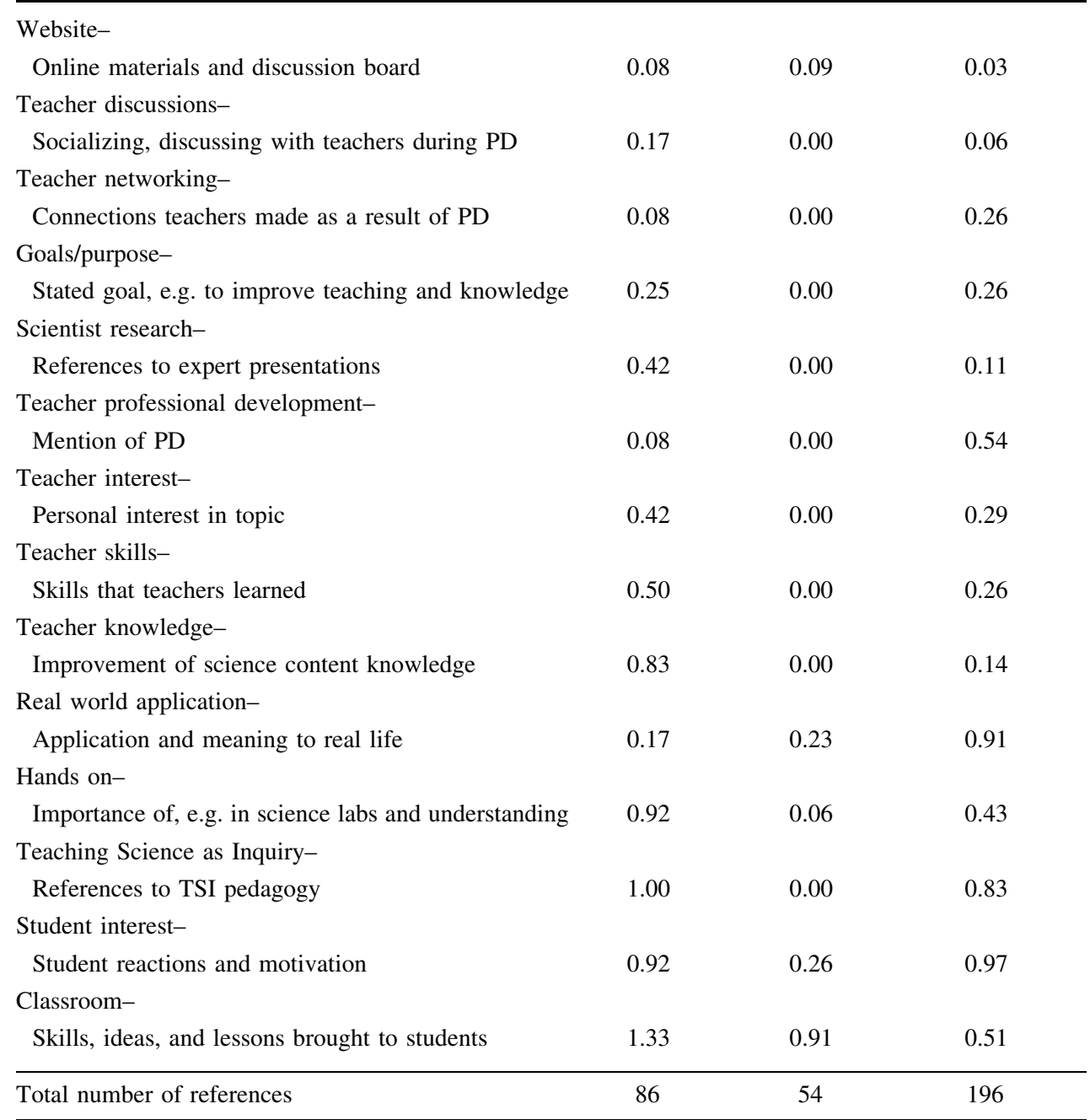

"Students were interested in graphing and came in during lunch and after school to use the computers. They loved it!"

"That day (of pinwheels) I could have walked out for 90 min, come back and they would have still been on task."

"I've never seen them (my students) work so long and hard and be bummed class was over."

Energy science content allowed teachers to engage students in real-world issues, making science and math relevant to students. Teachers wrote about tying energy issues to energy consumption in the classroom, to relevant newspaper articles, to events happening on their islands, and even to school related issues. Teachers commented that,
"Students were very motivated in doing the project since it was 'real' to them and they could see and measure their collected data."

"Students were so amazed at what was out there and the state of our world."

"Students were able to transfer, transition, synthesize their learning with their personnel lives."

Teachers also felt that their own content knowledge and enthusiasm was elevated by the TSI Energy PD. Teachers commented that,

"I had more fun, I learned more than the kids."

"I gained much more than my students did-I increased my interest and knowledge of conservation and efforts in sustainability." 
"I was inspired by the PD to have a sustainability focus in my class."

Teachers' said that using the TSI framework helped to guide their teaching by encouraging them to guide students through inquiry learning. Teachers commented that,

"I am excited to be able to continue to use the inquiry strategies learned in this course to improve the critical thinking and problem solving skills of my students."

"I found that prior to taking this professional development class, I wasn't teaching science as effectively as I was after learning about the different (TSI) phases of inquiry."

"Since completing the TSI course and implementing the inquiry lessons, I have gained more confidence in applying inquiry methods in my classroom."

"The TSI method provided for a rich learning experience... it allows students to be their own best critics, learning from trial and error, revising, reinventing $=$ success! It is a method for easier understanding not only of the concepts but of the scientific method and problem-solving process...strides and pace of learning are remarkable!"

\section{TSI Phase Framework Strengthened Teachers' Inquiry} Pedagogy

Of the 35 teachers that presented during the online Elluminate follow-up presentations, 18 discussed the TSI framework explicitly (discussion of inquiry was required, but the use of the TSI framework was optional). Of these 18 teachers, most discussed the phases and modes with similar frequency. On average, teachers described 3.4 out of the five TSI phases, with similar discussion frequency of initiation, invention, investigation, and interpretation (frequency per teacher $=0.89,0.72,0.78,0.83$, respectively). Instruction, however, was not discussed as often (frequency per teacher $=0.56$ ). The relatively infrequent discussion of the instruction phase is possibly because teachers are used to using instruction in their classrooms, especially teacher-to-student instruction.

The TSI phases appear to have helped teachers improve their process of teaching science through inquiry, especially for those novice to inquiry. For example, one teacher, who was new to teaching science, showed that she has begun to explore teaching science via inquiry using the TSI phases. This teacher used the TSI framework as the basis for structuring her Elluminate presentation, pointing out how she focused on the TSI phases and modes of inquiry throughout the activity. She detailed the instruction that was happening throughout the TSI process by showing a series of slides where she demonstrated what she and her students were doing in each of the phases.

The PD asked teachers to implement the TSI framework gradually, using new activities and incorporating elements of inquiry into existing lessons in a way that allows both teachers and students to build comfort and familiarity with the framework and with inquiry. Teachers expressed their increased understanding of engaging students in inquiry learning by discussing the order of their instruction. One teacher specified her goal as, "to teach energy concepts in a way that encourages scientific inquiry and sustainability... (She did this by) working in all phases of TSI inquiry in different ways and at different speeds." Another teacher commented that she "feels students would be more motivated to do research after the hands-on component" and that she wanted to move her students' research component to the final part of the activity. This shows growth in the teachers' understanding of the multidirectional flow of inquiry and how to build construction of knowledge with students.

Many teachers in our PD reported that, to them, inquiry had previously meant completely student-centered activities that often lack a unified learning goal. The purpose of the TSI framework is to give teachers tools to guide students through inquiry in a way that the students remain engaged, but with the understanding that teachers will have predetermined the content goal for the lesson. In other words, the teacher guides the class as a whole through the phases of inquiry, but learning paths vary between individual students. In order to ensure each student constructs knowledge relevant to the content goal, the teacher must recognize where students are in the TSI framework. For example, if a student needs to be re-initiated to the lesson, it is important for a teacher to recognize this and to be able to effectively use teacher-to-student instruction to guide the student. One teacher described her experience as,

"I had a hard time with the control factor in the classroom. I was nervous the students would be loud and I would become the observer. It was not like that at all. The students were engaged; you could walk around and talk to them without yelling at the rest of the class to be quiet, it was amazing...Interesting to see their reasoning, to let them talk and hear their reasoning and see what their thinking process was like...to see what students are thinking-it makes you go 'wow, that's really great, I never thought about doing it like that'. You see how engaged they are."

Another teacher who teaches at a project-based school, and who had clearly struggled with inquiry implementation, wrote in her pre-PD survey, "The whole point of 
inquiry is that you don't know what is going to happen, so it's really stressful to teach here (at this school) as you constantly run into problems you didn't expect." The TSI framework helped this teacher to categorize her teaching and structure her lessons so that she could more confidently teach through inquiry. She commented after the PD, "I realized what I was doing in class was inquiry...As far as learning goes, I've never done something like that before and I thought it was really awesome." This quote shows progress, but her later remark, "In terms of the inquiry part, as far as being neat and orderly and having a perfect little project-I'm kinda fumbling through that one," indicates that this teacher is still struggling with the integration of inquiry and project-based learning.

Teachers who explicitly used the TSI framework described an average of 2.7 of the ten modes. The classical inquiry mode, experimental, had the highest frequency of discussion at 0.611 per teacher, followed by technology, curiosity, descriptive, product evaluation, authoritative, deductive, replicative, and transitive (frequency per teacher $=0.5,0.28,0.28,0.28,0.22,0.17$, 0.06 , and 0 , respectively). Ironically, the transitive mode, which involves the application of knowledge from one discipline to another discipline, was discussed repeatedly by teachers with respect to energy science, but no teachers chose to categorize their lessons as encompassing this mode.

Focusing on specific modes during implementation appeared to encourage the use of inquiry instruction in a constructivist manner. For example, one teacher commented that he "focused on one to three modes (in each of his lessons)" -i.e. he used the Curiosity, Authoritative, and Descriptive in one lesson. One of the math teachers gave a revealing presentation about her lesson progression using wind power as a real-life problem for teaching linear and angular velocity. Although the teacher did not label her lesson presentation with the TSI phases, her discussion focused on the TSI phase of invention-the invention of definitions, hypotheses, methods, and formulas. Her lesson sequence provided an example of building knowledge through inquiry by presenting problems and guiding students though a cycle of investigations. The teacher pointed out that, in her lesson unit, the students invent their own definition of angular and linear velocity before the mathematical formula for linear and angular velocity is introduced so that students have experience with the concepts first. She also has students form groups to research their own questions and present their results to the class. Her wind power unit culminated in the students building a wind turbine to which they applied their knowledge of linear and angular velocity to determine wind speed.
Online Components Enhanced Participation

The addition of the online components appears to have reduced attrition and provided a mechanism for teachers to learn more content, share ideas, and provide peer feedback. Overall, 32 (out of 47) teachers completed all of the PD elements. Attendance at the initial workshop was $100 \%$ (of the teachers who signed up) and $78.7 \%$ participated in the Elluminate follow-up presentation where they presented their energy inquiry implementation to fellow teachers. $74.5 \%$ participated in the online peer forum, and $68.1 \%$ completed the online post-survey. Our overall retention in this iteration of the TSI Energy PD was higher (68 vs. $48 \%$ ) than the 2009 MEDB implementation of the Energy PD course, wherein $100 \%$ of teachers attended the 2-day workshop (held in the summer) but less than $50 \%$ attended a fall face-to-face follow-up where they were asked to share examples of their implementation.

Some teachers did express frustration with being (1) unable or unwilling to dedicate time to prepare a powerpoint presentation of their implementation, (2) uncomfortable with the technology (e.g. Elluminate) used for the remote follow-up, and (3) unable to participate during the Elluminate follow-up time slot. Nonetheless, the majority of teachers in our hybrid TSI Energy PD reported satisfaction with using remote technologies as it allowed them to (1) save time and money on travel, (2) reduce their energy use and carbon footprint, (3) use recorded guest presentations with their students, (4) refer back to content presented by energy experts, and (5) learn a new skill (referring to the use of Elluminate). We also found that the Elluminate interface enhanced both teachers' presentations and interaction between teachers. Because teachers had to provide a powerpoint presentation to share via Elluminate, the teachers' presentations were, overall, very well organized with a rich combination of inquiry reflection, student work examples, and discussions of lesson aspects that worked and/or needed improvement.

The ability of teachers to see one-another (via webcam) and to ask questions, provide comments, and give encouragement in the chat window of Elluminate also enhanced the online follow-up sessions (see Fig. 4). Teachers were required to use Elluminate emoticons (i.e. smiley faces, raised hands, thumb up/down, etc.) and to interact via the chat window at least twice during each Elluminate session. Teachers comments in the chat window fell into three main categories: questions about implementation (time, classroom management, worksheet construction, rubrics, etc.), questions about materials (type of materials, where to order supplies, size of materials, etc.), and praise (for ideas, inquiry use, and student learning). This type of peer feedback enhanced the PD and helped to 


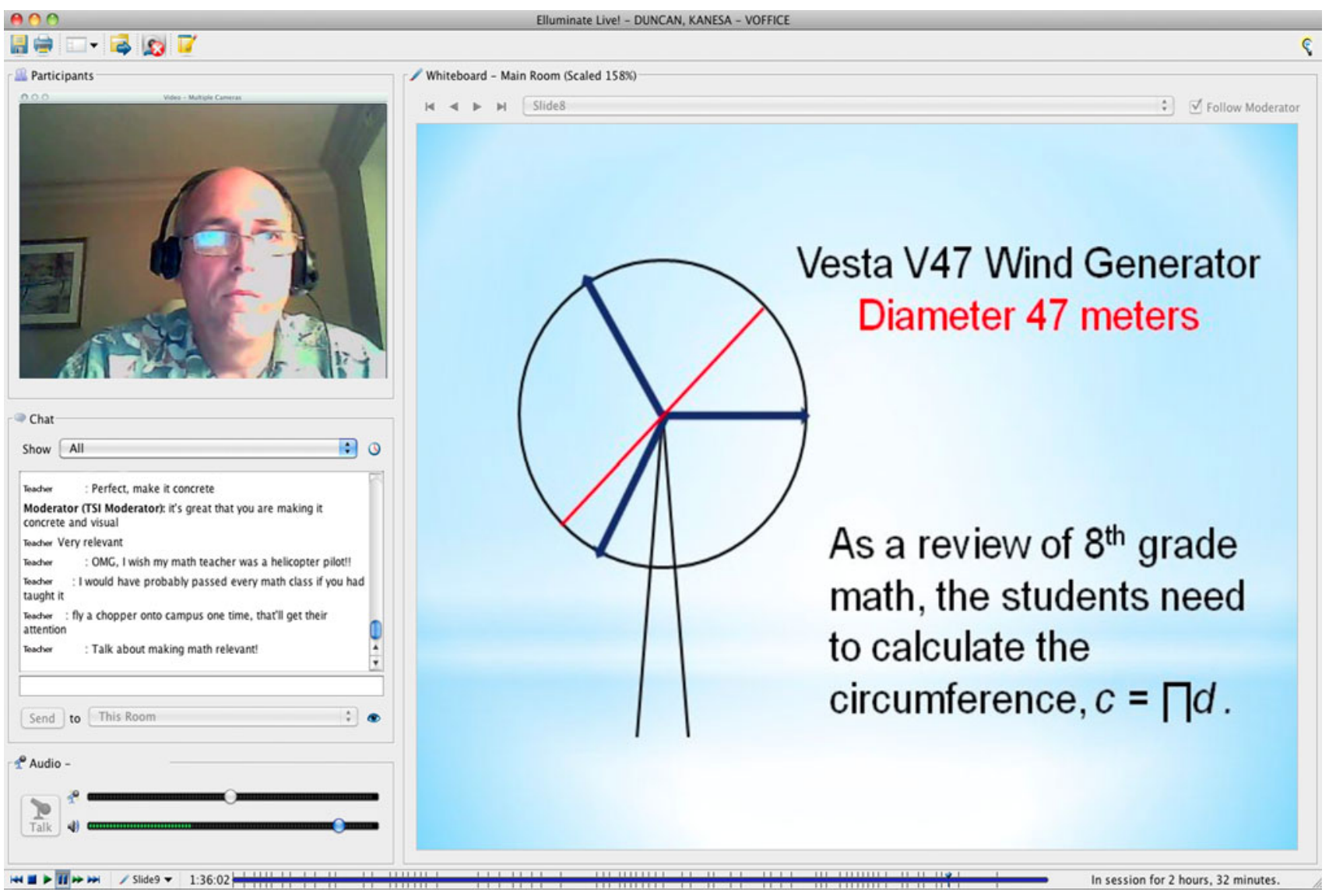

Fig. 4 A TSI teacher participant presents, via Elluminate, his implementation of wind power in his high school Algebra 1 class (9th grade) where students reviewed their 8th grade geometry (this was in the early fall) to calculate wind speed. The Elluminate webcam

connect teachers as a community following the initial workshop. It also enabled teachers to share their pedagogical expertise. One teacher comment is reflective of many others, "I enjoyed seeing how each person uses ideas differently." Examples of teacher chat window comments include,

"How did that rubric work, can you share it?"

"How long did the students have to work on their projects?"

"What type of glue did you use?"

"Was that pre-made or did you build it? Is that a 4 oz. container?"

"Great way to integrate science with math!!"

"You seem to have derived a great range of critical thinking, analysis, and evaluation"

"Perfect level of questioning and conclusions for the age level"

Teachers' subject area did not appear to influence participation level, however attrition did vary between island cohort (see Table 5 for breakdown by cohort). We suspect that retention would have been improved if we had been shot of the presenting teacher has been superimposed over the participant names (in the upper left "participant window", and participant names in the lower left "chat window" have been changed to "teacher" to hide individual identities

able to deliver all three PD courses within the academic school year. We delivered the first (Oahu) cohort during the academic school year from March to May and had $87.5 \%$ retention through the entire course, including post-course online surveys. The second cohort (Hawai'i) began in April and ran through July with $61.1 \%$ retention. The third (Kaua'i) cohort began in May and ran through September with $53.8 \%$ retention. Indeed, teachers in the later two cohorts expressed concern with the lack of time that they had to implement activities in their classrooms prior to the Elluminate follow-up presentations due to the timing (over summer) of the PD.

\section{Discussion}

The overarching goal of this PD was to increase teachers use of inquiry-based teaching in energy science. Energy concepts are extremely relevant from the international to the local level. Indeed, the connection of energy science to real life economics and ecology appealed to both teachers and students, and it allowed teachers to address multiple aspects 
Table 5 Participation in PD course segments by island cohort. Numbers of teachers beginning and completing each portion of the course are indicated

\begin{tabular}{|c|c|c|c|c|}
\hline & Oahu & Hawai'i & Kaua'i & Total \\
\hline Number began PD & $\mathrm{N}=16$ & $\mathrm{~N}=18$ & $\mathrm{~N}=13$ & $\mathrm{~N}=47$ \\
\hline Number completed PD & $\mathrm{N}=14$ & $\mathrm{~N}=11$ & $\mathrm{~N}=7$ & $\mathrm{~N}=32$ \\
\hline PD segment & $\%$ per segment & $\%$ per segment & $\%$ per segment & $\%$ per segment \\
\hline In person workshop & 100.0 & 100.0 & 100.0 & 100.0 \\
\hline Online peer forum & 100.0 & 61.1 & 61.5 & 74.5 \\
\hline $\begin{array}{l}\text { Elluminate (online) } \\
\text { follow-up presentation }\end{array}$ & 93.8 & 88.9 & 46.2 & 78.7 \\
\hline Online post-survey & 87.5 & 61.1 & 53.8 & 68.1 \\
\hline
\end{tabular}

Participation in each course segment is expressed as a percentage of the participants

of energy science, from windfarm businesses to classroom power needs. One of the most powerful findings from this study was the ability of the TSI Energy PD course to affect teachers' motivation to integrate energy science in their classrooms. Teachers repeatedly made statements about their enjoyment and motivation to teach energy science. We found that teachers were able to integrate general energy concepts, sustainability concepts, and specifics of wind and solar electricity generation across a surprisingly large range of disciplines, including mathematics, science, social studies and even culinary arts. A few of the teachers started class websites or facebook pages for their energy science projects, and one teacher even won a national award for his work.

To further develop the motivation and content knowledge of these teachers, we recommend the creation of a collaborative online environment where teachers can access both energy content and energy activities/lessons. The IEI curriculum provided teachers a starting point, and the supply kits that the teachers were given helped with implementation and provided access to materials and tools (i.e. solar panels and multimeters) that allowed teachers to conduct a variety of energy related projects. However, our data suggests that although teachers learned about energy and pedagogy in the course, most teachers in our course began and ended with less energy content knowledge than necessary for effective teaching of multiple aspects of energy science.

The teachers in our course, from various disciplines, were drawn to the topic of energy science, despite their apparently poor content knowledge of energy science. Our pedagogical content knowledge surveys also indicated that teachers' confidence in teaching energy science through inquiry is low compared to other subjects for which we have conducted TSI inquiry PDs (e.g. aquatic science and astronomy). This finding may be in part due to the nature and diversity of teachers that signed up for our course. Because we did not have a pre-requisite for the class, it is likely that many of our teachers signed up specifically because they had low-levels of knowledge in energy science. Our finding also supports other researchers who have reported that energy concepts are complex and difficult to understand conceptually (see Saglam-Arslan 2010).

In addition, the finding of low-confidence in inquiry among our TSI Energy PD teachers also points to the interconnected relationship between content knowledge and confidence in teaching through inquiry. Although we advocate in the TSI framework that the teacher does not need to know the "correct answer" before an investigation is undertaken or an idea is discussed with a class, we recognize that it is important for the teacher to understand fundamental concepts so as to be able to notice students' misconceptions or struggles and help redirect the students' learning. Based on teachers' survey answers, it is clear that the teachers feel they need more energy content knowledge to teach energy science effectively..

Our data further suggest that interaction with content experts may have lowered teachers' confidence in their ability to teach energy science. We suggest that this reflects (1) the complexity of energy science as well as (2) the short-term duration of our PD. We further suggest, however, that recognition of poor content knowledge may actually be beneficial to teachers in the long-term, especially if it promotes increased learning and knowledge acquisition. In fact, we advocate that the teachers' low confidence in energy science supports the development of more extended PD courses in energy science. Many teachers were self-professed novices in energy science, but even those with experience contracting or building alternative energy units on their personal property found that their knowledge of energy science and local utility grids was not as robust as they thought prior to the workshop.

Nevertheless, it was clear that the energy science content of the PD was attractive; teachers were excited to learn about energy science, and they were enthusiastic about talking with and learning from the energy experts. The teachers also repeatedly expressed "ah-ha" moments when working with the energy experts, signifying that the experts presentations 
helped teachers to better understand energy science. Thus, we believe PD can be used as an opportunity to bring together experts and teachers to help teachers gain content knowledge about energy science in very meaningful ways, provided there is ample time for teachers to digest and discuss content (see recommendations for teacher education on renewable and sustainable energy topics, Spiropoulou et al. 2007; Liarakou et al. 2009).

Overall, we found that the TSI inquiry framework had a positive impact on teachers' ability to teach energy science through inquiry. Teachers wrote and talked about inquiry extensively in their HIDOE portfolios and in their Elluminate follow-up presentations. The IEI curriculum and activities aligned well to the TSI goal of helping students learn about a topic (energy) while at the same time learning how we know what we know about energy and how to apply that knowledge to the real world. The TSI phases of inquiry helped teachers (especially those novice to inquiry) to structure their inquiry teaching in a guided manner, and their reporting of the phases gave insight into teachers' use of inquiry with their students. The TSI modes also appear to help teachers think about and detail the type of inquiry they are using with their students.

Despite these gains, we noticed that novice teachers did not appear ready to delve deep into the pedagogy of the framework, even among those who used the TSI framework to successfully increase the inquiry component of their teaching. More experienced teachers, on the other hand, applied pedagogical aspects of TSI but did not adopt the TSI language as readily as the novice teachers. This became interesting in our analysis because TSI language alone was not a good predictor of the quality of inquiry implementation and teaching. We noticed that when teachers relied heavily on the TSI language, they did not necessarily succeed in the implementation of high-level inquiry teaching. For example, the use of the TSI phases or modes as labels allowed teachers to put a descriptor on a strategy they were already using rather than working for actual transformation of teaching practice. In addition to looking at the use of TSI language, we therefore focused on teacher comments regarding order of instruction and teacher comments about helping to navigate and guide students toward understanding in a multidirectional learning cycle. These types of comments were indicative of teachers understanding inquiry and showed, in some cases, teacher progression from very teacher-centered instruction (e.g. directly telling students how to think) or unfocused inquiry (e.g. providing a completely open-ended activity) to more student- and content- centered inqiry. Teachers less successful at implementing inquiry did not use TSI language and continued to refer to inquiry as equal to hands-on, project-based, and/or chaos.

We have concluded from this course that both novice and experienced teachers appear to require more intensive training to optimally use TSI as a model for guiding students learning. The TSI phases and modes require meta-cognitive thinking by the teacher in planning and critical observation of student actions for teacher reflection. We have, therefore, begun to develop extended PD interventions that span the course of a full year and use multiple tools to address teacher and student progression through the TSI phases as well as teacher strategies for prompting students to move successfully through the TSI phases for increased understanding.

In terms of timing, we found that temporal proximity of the PD course to classroom implementation was beneficial for teacher retention in the PD course (and we therefore assume implementation in the classroom). Thus, PD conducted over the school year appeared to work better for teachers. Our use of online technology extended the PD past the two-day workshop component and allowed us to interact with teachers throughout Hawai ${ }^{i}$, where interisland travel costs often make follow-up PD components impossible. Similarly, in areas where distance or driving time may prohibit after school meetings, the use of online technology can extend PD experiences in meaningful ways. However, the reliance on digital technology probably also resulted in some attrition of teachers. Moreover, the use of online post-surveys resulted in mislabeling of post-surveys by six teachers, which made their surveys unusable for our analysis. We believe these types of issues, where in-person problem solving by PD facilitators is difficult, can be minimized by using additional organization for the online components,..

We recommend the use of both supplemental, online content as well as asynchronous online learning communities to extend the collaborative PD community. We also recommend the use of technology for synchronous followups and teacher sharing of classroom implementation. However, this recommendation comes with the caveat that we strongly advocate that ample time be dedicated to clearly outlining teacher expectations and to practicing technology with teacher participants during the face-toface portion, including the use of asynchronous online communication and resource tools as well as the synchronous virtual classroom. In addition, the use of a node or hub location for teachers to convene and jointly participate in the remote follow-up is beneficial for less technologically comfortable teachers (this can be hosted by a teacher participant if needed). We further advocate that, as PD is extended via technology, mechanisms are put in place to ensure collection post-survey data from all teachers who have completed the PD.

Acknowledgments We thank Dr. Francis M. Pottenger for his innovative thinking on teaching and learning science as inquiry, which led him to develop the TSI pedagogical model and our colleagues Lauren Kaupp and Mathew Lurie for their feedback on our use of TSI pedagogy. We also thank our energy experts who provided 
resources and information for our teachers. We thank University of Hawai'i at Mānoa professors Dr. Terry Surles and Dr. Eric Miller from the Hawai' $i$ Natural Energy Institute, Dr. Maxine Burkett from the Center for Island Climate Adaptation and Policy, and Dr. Gerard Nihous from Ocean Resources Engineering. We also thank Dr. Dora Yen-Nakafuji and Corinne Chang from the Hawaiian Electric Company, Andrew Yani, Spencer Toyama and Steve Valentin of Bonterra Solar, Dr. Bill Wiecking of the Hawai'i Pacific Academy Energy Lab, Markus Class of Class Solar, Laura Rogers of the Hawai'i Electric Light Company, Alan Nakagawa of Digital Science Solutions, Bob Conti of Kaua ‘ $i$ Community College, Steven Rymsha and Ray Mierta of the Kaua'i Island Utility Cooperative, and Dr. Adam Asquith from the University of Hawai 'i Sea Grant College Program for their time as energy science experts in this PD. We thank Kaua'i Sound \& Cinema for filming the energy experts and posting the videos online. Lastly, we thank the organizations and individuals responsible for providing us with venues to host our PD, including the Hawai'i Sea Grant College Program, Hawai'i Pacific Academy, and the Kaua'i Island Utility Cooperative. In addition, we thank the Hawai' 'i Department of Education and associated personnel for helping to facilitate the accreditation of our PD course. This research was supported by a No Child Left Behind Act reauthorization grant of the Elementary and Secondary Education Act II to KDS and approved by the University of Hawai'i at Mānoa Committee on Human Subjects, CHS\#15657.

Open Access This article is distributed under the terms of the Creative Commons Attribution License which permits any use, distribution, and reproduction in any medium, provided the original author(s) and the source are credited.

\section{Appendix}

Questions used in Pre- and Post-Surveys of Teachers, Sorted by Inquiry Application and Inquiry Knowledge Categories

\section{Inquiry Application}

Circle the answer that best reflects how you feel:

1) There are multiple ways to conduct inquiry in science classes.

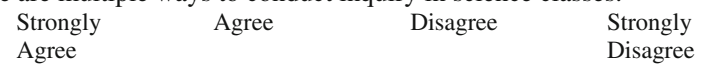

2) I have the skills needed to facilitate scientific inquiry with my students.

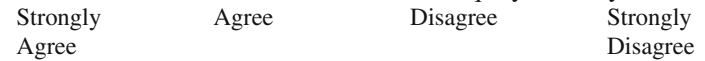

3) Inquiry can extend beyond science class into other topics. $\begin{array}{llll}\text { Strongly } & \text { Agree } & \text { Disagree } & \text { Strongly } \\ \text { Agree } & & \text { Disagree }\end{array}$

4) I feel confident in my ability to teach science through inquiry. $\begin{array}{llll}\text { Strongly } & \text { Agree } & \text { Disagree } & \text { Strongly } \\ \text { Agree } & & \text { Disagree }\end{array}$

5) In an inquiry classroom my students can instruct one another. $\begin{array}{llll}\begin{array}{l}\text { Strongly } \\ \text { Agree }\end{array} & \text { Agree } & \text { Disagree } & \begin{array}{l}\text { Strongly } \\ \text { Disagree }\end{array}\end{array}$

\section{Inquiry Knowledge}

Circle the answer that best reflects how you feel:

1) Inquiry occurs only when students engage in the complete scientific process. (note that this item was reverse coded for analysis.)

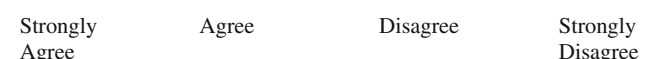

2) All people can use inquiry, not just scientists.

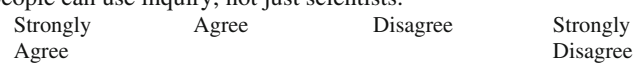

3) Students need a lot of background content information to do scientific inquiry. (note that this item was reverse coded for analysis.)

$$
\begin{array}{llll}
\begin{array}{l}
\text { Strongly } \\
\text { Agree }
\end{array} & \text { Agree } & \text { Disagree } & \begin{array}{l}
\text { Strongly } \\
\text { Disagree }
\end{array}
\end{array}
$$

4) Inquiry can include technological applications.

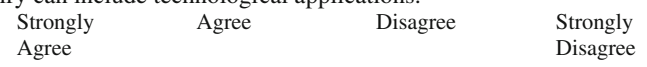

5) Hands-on activities are the same as inquiry.

(note that this item was reverse coded for analysis.)

$\begin{array}{llll}\begin{array}{l}\text { Strongly } \\ \text { Agree }\end{array} & \text { Agree } & \text { Disagree } & \text { Strongly } \\ & & \text { Disagree }\end{array}$

\section{References}

AAA (2011) Daily fuel gauge report. http://fuelgaugereport.aaa. com/?redirectto=http://fuelgaugereport.opisnet.com/index.asp. Accessed 14 Nov 2011

Afra NC, Osta I, Zoubeir W (2009) Students alternate conceptions about electricity and effect of inquiry-based teaching strategies. Int J Sci Math Educ 7:103-132

Chedid LG (2005) Energy, society, and education, with emphasis on educational technology policy for K-12. J Sci Educ Technol 14:75-85. doi:10.1007/s10956-005-2735-0

Duncan Seraphin K, Baumgartner E (2010) Your students as scientists: guidelines for teaching science as a discipline. In: Yagar R (ed) NSTA exemplary science programs series \#7: science in social and societal contexts. National Science Teachers Association (NSTA), Arlington, pp 33-50

Edelson DC (1998) Realizing authentic science learning through the adaptation of scientific practice. In: Tobin K, Fraser B (eds) International handbook of science education. Kluwer, Boston

Hawai'i Clean Energy Initiative (2010) http://www.hawaiiclean energyinitiative.org/. Accessed 1 Oct 2010

Liarakou G, Gavrilakis C, Flouri E (2009) Secondary school teachers' knowledge and attitudes towards renewable energy sources. J Sci Educ Technol 18:120-129. doi:10.1007/s10956-008-9137-z

Lincoln YS, Guba EG (1985) Naturalistic inquiry. Sage, Newbury Park

Manville J (2007) New survey finds most Americans incorrectly believe cars and trucks consume more energy than homes. http:// www.prweb.com/releases/energy/survey/prweb558373.htm. Accessed 10 Dec 2008

National Environmental Education \& training Foundation (NEETF) (2002) Americans' low “energy IQ:” a risk to our energy future/ 
why America needs a refresher course on energy. National Environmental Education \& Training Foundation, Washington, DC

National Research Council (NRC) (1996) National science education standards. National Academy Press, Washington, DC

Papini Warren D, Wilkins LR, De Rego F, Duncan Seraphin K (2011) Engineering energy solutions: facilitating hands-on design projects for middle and high school students via a statewide professional development program for teachers. Proceedings of the American Society For Engineering Education 2011 Annual Conference \& Exposition Conference. http://www.asee.org/ search/proceedings?fields[]=author\&search=kanesa\&commit= Search. Accessed 31 Oct 2011

Ragin C (1987) The comparative method: moving beyond qualitative and quantitative strategies. University of California Press, CA

Saglam-Arslan A (2010) Cross-grade comparison of students' understanding of energy concepts. J Sci Educ Technol 19:303-313. doi:10.1007/s10956-009-9201-3

Scarlett T (2008) An exploratory study of the impact of two versions of inquiry-based science program professional development on teachers' perceptions of their Pedagogical Content Knowledge. University of Hawai'i at Mānoa, Honolulu

Shelton S (2008) Energy pulse survey shows mix of rising awareness, confusion about energy and renewables. http://www.shelton
groupinc.com/energypulse/press_releases/EP08_renewables. Accessed 15 Jan 2009

Spiropoulou D, Antonakaki T, Kontaxaki S, Bouras S (2007) Primary teachers' literacy and attitudes on education for sustainable development. J Sci Educ Technol 16:443-450. doi:10.1007/ s10956-007-9061-7

Tytler R (2002) Teaching for understanding in science: constructivist/ concepetual change teaching approaches. Aust Sci Teach J 48(4):30-35

U.S. Department of Labor (2010) Geospatial technology competency model. Career onestop. http://www.careeronestop.org/compe tencymodel/pyramid.aspx?GEO=Y. Accessed 6 Jan 2011

van Zee EH, Hammer D, Bell M, Roy P, Peter J (2005) Learning and teaching science as inquiry: a case study of elementary school teachers' investigations of light. Sci Educ 89(6):1007-1042

Windschitl M, Dvornich K, Ryken AE, Tudor M, Koehler G (2007) A comparative model of field investigations: aligning school science inquiry with the practices of contemporary science. Sch Sci Math 107(1):382-390

Zembal-Saul C, Munford D, Crawford B, Friedrichsen P, Land S (2002) Scaffolding preservice science teachers' evidence-based arguments during an investigation of natural selection. Res Sci Educ 32:437-463 